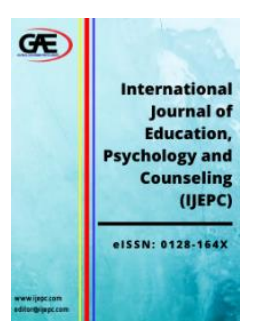

\author{
International Journal of Education, \\ Psychology and Counselling (IJEPC) \\ Journal Website: http://ijepc.com/ \\ eISSN: 0128-164X
}

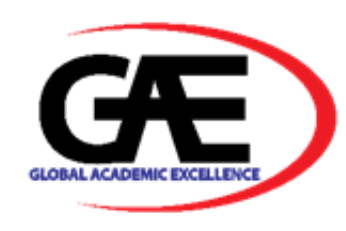

\title{
PSYCHOLOGICAL ADJUSTMENT OF MUSLIM CHINESE INTERNATIONAL STUDENTS IN MALAYSIA
}

\author{
Sainula Tuerxun ${ }^{1}$, Nik A. Hisham ${ }^{2}$, Ridhuan Abdulla ${ }^{3}$, Nur Syahidah Khalid ${ }^{4}$
}

1 Education Faculty, International Islamic University, Malaysia

Email: zainuramalika@gmail.com

2 Education Faculty, International Islamic University, Malaysia

Email: nikahmad@iium.edu.my

3 Education Faculty, International Islamic University, Malaysia

Email: ridhuanabdullah@iium.edu.my

4 Education Faculty, International Islamic University, Malaysia

Email: syahidahkhalid84@gmail.com

\section{Article Info:}

\section{Article history:}

Received date:26.11.2019

Revised date: 29.12 .2019

Accepted date: 23.01 .2020

Published date: 15.03 .2020

\section{To cite this document:}

Tuerxun, S., Hashim, N. A., Abdulla, R., \& Khalid, N. S. (2020).

Psychological Adjustment of Muslim Chinese International Students in Malaysia. International Journal of Education, Psychology and Counseling, 5 (34), 60-79.

DOI: $10.35631 /$ IJEPC.534005.

\begin{abstract}
:
International students are growing in numbers in Malaysian college and university campuses since the commercialization of education at the tertiary level introduced in the 1990s. More significantly, there is an increase in the Muslim student population as more and more young Muslims come to Malaysia from different parts of the world. For example, there is a substantial increase in Muslim students from the People's Republic of China (PRC) who see Malaysia as a peaceful and developing Muslim country. The aim of this qualitative study is to explore the thoughts and experiences of Muslim students from China studying at different Malaysian universities. Six Muslim students from RPC were interviewed in this study, and based on the data obtained from the interviews, the findings were categorized into several themes. Most Muslim-Chinese students found it difficult to adjust to the new environment, especially in terms of climate, food, and infrastructure. The students also found that language was a barrier in their interactions with the locals. At the individual level, the students suffered from loneliness and homesickness and also found that their financial situation posed a challenge. In the course of the study, several coping strategies were identified that the students had adopted in their pursuit of knowledge in Malaysia. On the other hand, they felt supported in their efforts to adjust to living in Malaysia by university management, faculty members, local students, and friends. Overall, the students concluded that Malaysia is a peaceful and beautiful country characterized by the kindness, tolerance, and helpfulness of her people. Finally, the students recommended that services and facilities should be improved for all international students in Malaysia.
\end{abstract}




\section{Introduction}

In response to the globalization and internationalization of education, international student enrolment in higher learning institutions (HLI) is increasing (Altbatch et al., 2009; Zolfaghari et al., 2009). By definition, international students are those students pursuing their education while residing temporarily outside their homeland (Paige, 1990), cited by Lin and Yi (1997). In terms of economics and culture, the host country benefits from international students. Besides, international students also help to create an educational exchange environment, which promotes diversity and multiculturalism and can help resolve a shortage of labor in some sectors of the host nation's economy.

Bohm et al. (2002) reported that by the year 2000, about 1.8 million international students would be studying in post-secondary institutions and projected the number to increase fourfold by 2015. The same trend can be observed in Malaysia which enjoys a favorable reputation as a peaceful country among the Muslims and thus attracts many Muslim students from all parts of the world including China.

Adjusting to new ways of life is ever challenging for international students (Mori, 2000; Gebhard, 2012) due to the complexity involved in adjusting to a new culture, language, and social and academic environment (Dyson and Renk, 2006). Thus, in many cases maladjustment creates stressors that impact negatively on the students' academic performance (Gebhard, 2010; Kuo, 2011). Moreover, in some cases, it may disrupt interpersonal relationships (DeAraujo, 2011), health problems, loneliness, and alienation (Sherry et al., 2010; MyersWalls et al., 2011). On the other hand, the adjustment process provides ample opportunity for self-development and appreciation of other cultures over time. Some international students believe that the process of internalizing another culture affects them positively and views it as an agent of personal educational and development.

However, among the few studies conducted in Malaysia focusing on international students and their adjustment challenges, not a single study has examined the adjustment challenges experienced by Muslim-Chinese international students in Malaysian universities and colleges (Yusliza, 2011). In addition, most of the studies have followed a quantitative rather than a qualitative approach.

Yet, several existing studies have related the issue of adjustment to cross-cultural factors such as exposure period to the locals, duration of stay, financial support, accommodation, and socioeconomic well-being (Mehdizadeh \& Scott, 2005). According to Malakolunthu and Selan (2011), the adjustment challenges of international students in Malaysia are mainly related to their academic, religious, personal, social, financial and language problems.

\section{Objective of Research}

Considering that adjustment constitutes the major concern among international students, this study has adopted the case-phenomenological study of the experiences made by MuslimChinese students in terms of their adjustment challenges and coping strategies. This study explores the experiences of Muslim-Chinese students who were studying in Malaysian colleges 
and universities. The study findings show how their experiences were influenced by their perceptions, especially in terms of their thoughts and feelings about living as international students in a foreign land.

The main question of the study is to explore how Muslim-Chinese students adjust to their new life in Malaysia. To assist in answering the main question, other objectives were developed which are as follows:

1. How do Muslim-Chinese students experience adjustment problems in Malaysia?

2. How do Muslim-Chinese students react to challenges as international students in Malaysia?

3. How do Muslim-Chinese students overcome these challenges?

4. What are the underlying circumstances that influence their adjustment?

5. What support systems are available to the Chinese-Muslim students?

6. How do the challenges affect their social and academic life?

7. What are the positive lessons learned by the Muslim-Chinese students after completing their process of adjustment?

\section{Methodology of Research}

A qualitative research design was adopted to investigate the adjustment experience of ChineseMuslim students in Malaysia as this method provided better outlets for the participants to relate their experiences. Creswell (2013) remarked that transmitting the real nature of the experience of several people with a specific social reality constitutes the objective of phenomenological research. In addition, the study also focuses on Chinese-Muslim students as a case study for the research. The case of this social phenomenon among Chinese-Muslim students on adjustment was specifically designed to gather data to achieve a better understanding of the said and intended to incorporate the perspectives of the individuals living this phenomenon first-hand.

Six individuals volunteered to participate in this study; three males and three females from three different universities and colleges in Malaysia. The participants were mainly Uyhgur Muslims, an ethnic minority group in China. They were born and raised in China with a minimum and maximum age of 21 and 40 years and a mean age of 29.6. Three of the participants were single and three were married with children. All of them had studied in Malaysia for more than three years. Three of them were undergraduate students and the other three were postgraduate students. The participants were recruited using snowball sampling through networking and word-of-mouth meaning that they were recruited on the recommendation of another participant. An email was sent, or a call was made to acquaint the prospective participants with the nature of the study and its voluntary nature.

Table 1: Participant Data

\begin{tabular}{|c|c|c|c|c|c|c|c|}
\hline NO & Name & Age & Ethnicity & Origin & $\begin{array}{c}\text { Marital } \\
\text { status }\end{array}$ & $\begin{array}{c}\text { Education } \\
\text { level }\end{array}$ & $\begin{array}{c}\text { Length } \\
\text { of } \\
\text { residency }\end{array}$ \\
\hline 1 & Rose & 34 & Uyhgur & XinJiang & Married & Master & +7 years \\
\hline 2 & Iris & 21 & Uyhgur & XinJiang & Unmarried & Bachelor & +8 years \\
\hline 3 & Lily & 22 & Uyhgur & XinJiang & Unmarried & Bachelor & +4 years \\
\hline 4 & Alkaid & 26 & Uyhgur & XinJiang & Unmarried & Bachelor & +5 years \\
\hline
\end{tabular}




\begin{tabular}{|c|c|c|c|c|c|c|c|}
\hline 5 & Merak & 40 & Uyhgur & XinJiang & Married & Phd & +10years \\
\hline 6 & Mizar & 39 & Uyhgur & XinJiang & Married & Phd & +9years \\
\hline
\end{tabular}

The data was collected through semi-structured interviews conducted at the respective colleges and universities. Each interview lasted between 120 and 150 minutes. The interviews were conducted in English and Uyhgur language before being recorded and transcribed for analysis. The data analysis was based on the method highlighted in the Three C's of Analysis by Lichtman (2006). Each interview was transcribed and reviewed by field experts, and then the data were coded, categorized, and conceptualized in themes. The themes extracted from the findings were: (1) reasons to study in Malaysia; (2) challenges encountered; (3) coping strategies; (4) support system; (5) positive growth; and (6) recommendations for colleges and universities. The six themes are more fully described in the following sections and are also listed in Table 2 below.

Table 2: Sample of Adjustment Themes

\begin{tabular}{|c|c|}
\hline Reasons for studying in Malaysia & $\begin{array}{l}\text { 1. Improve English } \\
\text { 2. Malaysian degree would provide 'more } \\
\text { opportunities'/further career } \\
\text { development/gateway to other countries } \\
\text { 3.Personal development } \\
\text { 4. Lower tuition fees } \\
\text { 5. Parental choice } \\
\text { 6.Islamic environment } \\
\text { 7. Easy visa requirements }\end{array}$ \\
\hline Challenges & $\begin{array}{l}\text { 1. Personal living challenges } \\
\text { * weather } \\
\text { *food } \\
\text { *financial } \\
\text { 2.Psychological adjustment challenges } \\
\text { * homesickness and loneliness } \\
\text { *stress } \\
\text { 3. Social cultural adjustment challenges } \\
\text { *General interaction } \\
\text { *Interaction difficulties with local students } \\
\text { 4. Academic adjustment challenges } \\
\text { *language } \\
\text { *new education system } \\
\text { *academic stress } \\
\text { *interaction with faculty staff }\end{array}$ \\
\hline Coping Strategies & $\begin{array}{l}\text { 1. Problem focus } \\
\text { *Direct action } \\
\text { *Help and social support seeking } \\
\text { 2. Emotional focus } \\
\text { *Avoidance } \\
\text { *Emotion discharge } \\
\text { *Positive reappraisal }\end{array}$ \\
\hline
\end{tabular}




\begin{tabular}{|c|c|}
\hline & $\begin{array}{l}* \text { Endurance } \\
* \text { Prayer }\end{array}$ \\
\hline Facilitators \& barriers & $\begin{array}{l}\text { 1. Facilitators } \\
\text { *Islamic environment } \\
\text { *Good education } \\
\text { 2. Barriers } \\
\text { *homesickness } \\
\text { *food } \\
\text { *climate }\end{array}$ \\
\hline Obtained Support & $\begin{array}{l}\text { *Self-Motivation } \\
\text { * Support from Family } \\
\text { * Support from Friends } \\
\text { * Support from Professors } \\
\text { * Religion and Prayer } \\
\text { * Support from Office of International } \\
\text { Student Affairs }\end{array}$ \\
\hline Experienced growth & $\begin{array}{l}\text { 1. Academic ability } \\
\text { 2. Changed ways of thinking } \\
\text { 3. Maturation and independence } \\
\text { 4.Islamic knowledge }\end{array}$ \\
\hline
\end{tabular}

\section{Theoretical Framework}

\section{U-Curve Hypothesis of Cultural Adjustment}

The U-Curve Hypothesis (Cushner, McClelland, \& Safford, 2003) was used to focus on the understanding of the acculturation aspect of adjustment among our participants. The hypothesis could help to assess the needs of our students by identifying where they were positioned on the U-Curve Hypothesis. Also, it is advantageous knowing this hypothesis as it allows the university administrators and lecturers to determine ways in which to help their international students and provide a more accommodative learning climate. At the same time, the hypothesis helps understand the international students' challenges and their specific approach to develop their own coping strategies. Due to their lack of proper adjustment to the new home, international students might face failure and experience hopelessness. 


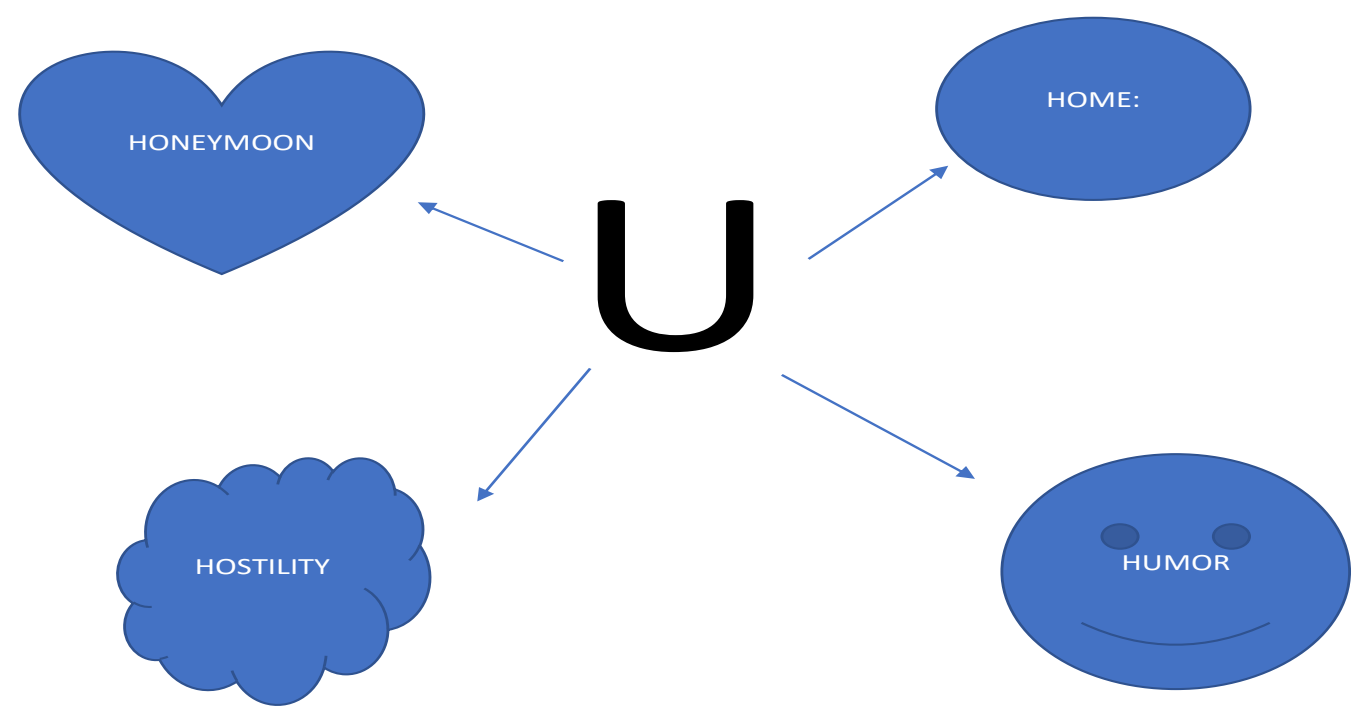

Figure 1: U-Curve Hypothesis

The U-Curve Hypothesis consists of four phases that extend over some period of time depending on the duration of the stay in the host country. The first phase is called the 'honeymoon' phase as the newly arrived students feel a sense of exhilaration and happiness. During this initial period, the surrounding appears promising to the newcomer since the new culture has a lot of good learning experiences to offer. The students, however, begin to feel hostility towards their new environment once they realize the reality of the new culture and its drawbacks and limitations. The students may begin to feel frustrated, despite their best efforts, their needs are not accommodated. This sense of hostility stems from the cultural mismatch between what they had before (at home) and what they have now (abroad). They will feel alone, alienated, frustrated, and angry. The 'humor' phase begins when the newcomers learn how to adapt to the new culture through reflection and a positive mindset. They start to see a lot of opportunities and compare the new and the old culture based on a more positive orientation and perspective. The final stage begins when the newcomers could have adapted to the differences of the two cultures and is characterized by the acceptance of cross-cultural differences in an affirmative manner.

\section{Findings}

\section{Reasons to Study in Malaysia}

The interviewed Chinese-Muslim international students shared many reasons for choosing Malaysia as their study destination, among them the affordable tuition fees and living cost, English as a medium of instruction, the Islamic environment, the readily available study visa, self-development, and parental choice. Lily, a second-year student expressed:

Ah, for me, why do I choose to study in Malaysia is, uh, because if I chose to study in a European country, I have to use a dollar or something like that. So, in Malaysia tuition fees and living fees are cheaper.

Alkaid, a bachelor's student, remarked:

Most of Malaysian education is in English. That helps when you go to other places, and, uh, some of the universities' courses are in line with the British education system, so that is also recognized in many countries. It would help us to have more job opportunities. ...I chose to study in Malaysia because it was easier to get a visa and it's cheaper compared to Western countries, cheaper education. 
Merak, a former PhD student, shared:

One of the greatest advantages of studying in Malaysia was that it's a Muslim country, so we can practice our religion freely. We can perform our prayers everywhere, whenever we go, and another reason was it would be easier to find halal food ...That was the one of reasons we chose to study in Malaysia in the first place.

Lily, a second-year student, shared:

Before I came here, I heard that Malaysia has a very good education, and also, I want to develop my social skills and independence skill because, because when you go to other countries, you have to do everything by yourself ... We have to make decisions for everything ourselves and we'll learn a lot of things which our parents or teachers never can teach us, so I chose to come to Malaysia.

Iris, an undergraduate student, explained:

It's actually, it was my father's choice to send me to Malaysia to study because he really likes the weather in Malaysia. Actually, yeah, the weather, he found Malaysia has such fresh air, yeah, that's all. yeah, it's my father's choice.

\section{Challenges}

There were in-depth discussions among the participants in response to the question of the challenges they were facing as international students in Malaysia. The various challenges shared by the participants were grouped into general living challenges, psychological challenges, social-cultural challenges, and academic challenges. Each of the following main categories also features the relevant sub-topics.

\section{General Living Challenges}

\section{Climate and Food}

The Chinese-Muslim international students reported that among the biggest challenges was to adjust to the tropical climate and the local foods and beverages. The participants admitted that it was hard for them to adjust to the high temperatures $(25 \mathrm{C}-30 \mathrm{C})$, the high air humidity $(80 \%$ $90 \%$ humidity) and the ever-changing weather depending on the seasons. The participants also commented on the local food which basically consisted of rice and spicy chicken or fish.

One participant shared how he experienced the local climate:

When I started my study in Malaysia, my biggest challenges were the tropical climate ... and then the food .... The tropical, humid climate was so different from our homeland and it was very, very difficult to adapt myself to the climate ... That was one of main challenges.

He continued,

Another problem I faced is the food of Malaysia ... because of the huge differences between Uyhgur food and Malaysian food. It was not an easy thing to adapt to, and I had to try, uh, almost every dish of Malaysian food ... So, I had to, uhm, uh, turn to other food like Albanian food, Arabic food, and some other countries' food. 


\section{Financial Support}

Among the six students, only the married ones and those with family reported that they were experiencing financial difficulties while studying in Malaysia. Rose explained that as a married student, living abroad and having kids posed a great challenge to her. She said,

We have financial problems. In the beginning, we don't have much of a problem financially because our parents support us. But since we are married now, we are adults. We can't always ask for money from our parents. So, my husband earns money and just supports me to continue my studies here.

\section{Psychological Challenges}

\section{Homesickness and Loneliness}

The students also reported that they experienced psychological adjustment problems, and some admitted to feeling homesick and lonely. Merak commented that:

As a foreign student in Malaysia, we miss our family, we miss our home country, and we have to manage our homesickness, trying to visit our friends ..., trying to socialize with them.

Alkaid shared a similar experience and commented:

Like most students who study abroad, uh, I was far away from my family so, uh, I'm homesick sometimes, and it's challenging to get used to the new environment, and it's a different language, different culture to adapt.

\section{Stress}

The stress of Muslim-Chinese international students participating in this study mainly came from their lacking English skills and their inability to interact with the local students. The anxiety of not be able to communicate well with others somehow reflected their psychological well-being. This section will discuss this matter at length, in addition to the students' academic challenges.

\section{Social and Cultural Challenges}

Social and cultural adjustment is defined as behavioral skills and the ability to fit in or interact successfully with the members of the host culture. In this study, we found that the participants' social and cultural adjustment was affected by factors such as culture and value differences, interaction with local and other international students, and language deficiency.

In this study, the participants shared that it was hard for them to be accepted by local students as the local students seemed to prefer being among their own peers. The participants assumed that their mastery of the local language (Bahasa Melayu) and English was the reason for this predicament. However, they identified one commonality between themselves and most Malaysians, which was that they shared the same religion, Islam. This constituted the 'meeting point' that allowed some interactions to take place between them and the local Malays.

Some participants felt that they could befriend local students and learn about the local multiethnic Malaysian culture and the different languages are spoken in Malaysia. Alkaid had experienced certain difficulties when trying to interact with the local students at his university and tried to explain the reason behind it: 
Uh, the main cultural challenge would be: It's hard to belong to the group with locals, and that's because when we are in Malaysia. We study in English, so our daily life is also in English. Uh, but for locals, they have their own language, Malays speak Bahasa Melayu among themselves, uh, so it's hard to be part of, to mingle together with locals.

He admitted that he didn't know how to speak Bahasa Melayu yet had also not tried to learn it since it was not a compulsory subject. He was, however, quite certain that if he had learned Bahasa Melayu as a student, his situation would be different. He explained:

I can say I didn't overcome the interaction difficulty, my main challenge, because I did not study the Bahasa Melayu, it was not required to learn. I think it will be different if I studied, if I speak Bahasa Melayu and then, maybe that is easier culturally.

Alkaid believed that if he learned to speak the local language (Bahasa Melayu) he would not find it so hard to interact with other local students. Iris, on the other hand, was very much willing to learn Bahasa Melayu, which allowed her to make more local friends and helped her to be accepted into their circles and establish more personal friendships with them. She explained:

Now I am close with my Malay friends because I want to learn how to speak Bahasa Melayu, so these Malay friends have been helping me. Like when we go chill together, they are ... like helping me with my language problems. Uh, they treat me as one of them.

\section{Academic Challenges}

There are four subcategories to the academic adjustment concerns in this study: language, academic stress, academic adjustment and interaction with the faculty members.

\section{Language Barriers}

Another common comment made by the participants was that learning English was quite a difficult and challenging task. They felt that what they had been taught in the English language program was different from what they had to study now. The students reported that they had had considerable comprehension problems in the early stage of their study, especially in their first year. To comprehend, to understand and to communicate in English was a big challenge for them. Rose recalled her initial experience as a first-year student at university and summed up her thoughts by saying:

I was stressed because my English was also not good. So, I felt very lonely. The English language is not our first language, so sometimes I couldn't understand what our lecturers said. Sometimes I felt that our lecturers spoke very fast and didn't clearly explain ... It was hard to understand the difficult vocabulary, so sometimes we don't understand the deeper meaning of the knowledge.

\section{Academic Stress}

According to Wan, Chapman, and Biggs (1992), academic difficulty constitutes the main cause of stress experienced by international students. Academic difficulties caused by academic cultural differences and by language proficiency are also often related to stress (Brown, 2008a). In this study, most of the respondents reported that at the beginning of their study, they had felt stressed due to their poor language proficiency and their study workload. 
Mizar, a PhD student, had already studied English before coming to Malaysia, which meant that he could finish the English language program in a short time and quickly proceed to commence his studies at the faculty. He shared:

Although I got band six after studying English language for one semester in the English Language Department, after joining my faculty, I found out that my English was very poor. It was hard to understand the course content. It made me frustrated.

The participants were satisfied with the course content and the higher education system in Malaysia in general. The difficulties in their educational environment stemmed mainly from their English language deficiency, which made it difficult for them to understand their classes. Lily shared:

Malaysian students at university, they've learned the basics about Economics in their high school or college, so when the teachers teach us about this knowledge... so, the teacher just skips some information. That is most challenging for us because as international students, we don't have that background. So, sometimes like it's difficult for us to understand the lessons delivered in class.

Merak reported that he had experienced difficulty in understanding how to do assignments properly as he had never learned how to write them in the first year of study. He explained:

When I came to Malaysia, initially, I was having some difficulties to adapt to the education system in Malaysia, ...., uhm, because the system in Malaysia is so different from ours in China. And I, uhm, try to, you know, to catch up with the Malaysian students, uh, to the best of my ability. ... For example, in the first semester, I was enrolled in the Political Science Department. Uhm, I submitted an unsatisfactory assignment to my teacher, and the teacher explained it and I found out that I didn't understand the course requirement, assignment requirement or both, because of the difference in education system.

He continued describing his experience with his first course assignment:

In our university, we didn't use to have long writing assignments when I studied in my homeland, so that kind of writing assignment was new to me. So, when the teacher asked us to write an assignment about a book, you know, review a book, I wrote only two pages about one book and I thought it was very good ... So, that was one of those difficulties of studying and adapting myself to the system.

\section{Relationship with Lecturers}

In terms of interacting with the academic staff, the participants claimed that they had a good relationship with them and also with their academic advisors. However, one interviewee felt too shy to talk to her lecturers; whenever she had a problem, she would ask her classmates instead. Rose disclosed that

My lecturers helped me a lot because I have two kids. Sometimes I can't submit my assignment on time and sometimes I don't understand the content. At that time my teachers are very patient. Not only one teacher, all teachers, encouraged me and helped me. With their help, al-hamdu-li'llah, I finished all my assignments. 


\section{Coping Strategy}

The students' coping strategies were reported based on Lazarus and Folkman's (1984) two coping strategies of problem-focused coping and emotion-focused coping. Problem-focused coping targets the causes of stress in practical ways. It tackles the problem or stressful situation that is causing stress directly and consequently reduces stress. Problem-solving strategies aim to remove or reduce the cause of the stressor including problem-solving, time management, and obtaining instrumental social support. Emotion-focused coping involves trying to reduce the negative emotional responses associated with stress such as embarrassment, fear, anxiety, depression, excitement , and frustration

For the purposes of this study, the students were asked to identify the problems and difficulties they were facing or had faced before. Then the participants were asked to discuss their coping strategies and beliefs. Their primary help-seeking modes were soliciting and securing support from co-national friends and family members. They dealt with other problems by using direct action to cope. Both problem-focused and emotion-focused coping strategies were used. From the collected data the researcher learned that most participants would try to solve small problems that they felt they could solve by using either direct action or seeking help from others. The emotion coping in this study included avoidance, discharging emotions, positive reappraisal, endurance, and spirituality.

In this study, three students avoided their negative emotions, and two students discharged their emotions through engaging in various activities such as sports and socializing, which reduced feelings of homesickness, loneliness, study stress, communication problems (language barrier), and financial issues, while one student engaged positive reappraisal to motivate herself.

\section{Problem Focused Coping}

\section{Help Seeking Belief}

In general, most Chinese international students choose not to use professional services to deal with their emotional and personal problems. Instead, they tend to reduce their stress on their own and with the support of their families, friends or religious leaders (Cheung, 2011)

In this study, the Muslim-Chinese international students did not know much about the counseling services available on campus, although they thought that counseling would be helpful. However, they were reluctant to go for counseling when they felt troubled and thought that only those with mental illnesses went to see a counselor. Mizar commented:

Counseling service is actually good if they can run it properly. But for me, I will not choose to go for counseling because I'm an introverted person. I don't share my problems with strange people. I will not. I will not." Merak shared, "During my study in Malaysia, I had not use any counseling services on campus. Might be because I didn't encounter any emotional or mental problems, you know. Uhm, other things that need counseling, maybe because I ignore the services to improve my wellness in Malaysia.

\section{Direct Action}

When it comes to the lifestyle adjustment to food, climate and finances, the participants chose to take direct action in order to deal with their stress by trying to solve their problems on their own. Merak stated: 
When it comes to difficulty about the climate, I tried to stay away from humid places ... from going outside for a long time, and I tried to stay inside certain places. And, of course, staying long hours with certain air-conditioned facilities... When it comes to food, we could turn to other food instead of Malaysian food, because wherever you go you could find many other foods. And, of course, we don't altogether ditch Malaysian food. We highlight several dishes in Malaysian food like nasi goreng pattaya.

\section{Help and Social Support}

When it came to their financial problems, the participants were ready to ask help from their parents or tried to obtain scholarships and turned to the International Student Affairs department to ask for their assistance. Mizar shared:

Well, when I have a shortage of money, I try to settle on my own. Since we are adult it's hard to ask for money from our parents all the time, so I have a part-time job, and also do some business. If by doing all this I still can't settle my problem, then I turn to my parents.

Rose felt guilty when talking about her financial difficulties. She admitted that:

My husband and I, both came to Malaysia to study but because of financial difficulty, my husband quit his studies to support my studies and our family. But sometimes I wasn't able to pay the tuition fees, so I went and ask for help from the university.

\section{Emotional Coping}

\section{Emotion Discharge}

Discharging one's emotions constitutes a different coping response than acting on the problem itself. It allows the individual to manage his or her feelings which might otherwise become overwhelming. Lily chose to do physical exercise as a means to help manage her stress. After having been able to release her stress, she chose to seek the help and support of her friends. She explained:

When I faced lots of problems by myself, most of things I do are cry and then try to do exercise because it makes me feel relaxed. And then give me some time to think about how to solve the problems... I like to talk to my friends because when I talk with my friends I feel more relaxed and then maybe my friends can give me some advice so that I can solve my problem.

\section{Avoidance and Endurance}

In terms of social interaction with local students, the participants chose to use avoidance as a coping strategy to deal with the difficulties (rejection, disinterest) they faced when interacting with the local students. They also engaged in various activities to avoid anxiety, depression, frustration, and other discomfort resulting from stress or worries. Alkaid expressed:

Huh, I just talked with my family, I hung out with my friends. We talked about our home together, huh, like the story back home. Those are, yeah, I think that's how we did it.

In terms of social interaction with his peers, he had soon realized that his situation was more like that of other international students. He thought that the foreign students understood each 
other better and had more sympathy for each other's plights. Since he could not speak Bahasa Melayu it was hard for him to make friends with the local students. He explained:

Huh, most of the time, I was interested in international students because we're all in a similar situation. We're all far from home. We're all different from local students. That makes us similar in that way. That helps in my situation.

Enduring stress constitutes an important way of coping with stress. The students believed that challenges, obstacles, and difficulties were part of life. If they could endure these difficulties, life would go on and their situation would eventually change. Mizar, a rather quiet and independent young man, liked to read in order to distract himself from his difficulties and forget about them, at least for some time. He shared that:

I read books. I've always been a book worm. It's my friend and takes me away from reality for a short time, thus I feel better. But no matter what, I must cope with this condition, and human beings are adaptable.

According to Mizar, books could help him forget but only for some time. Eventually, he would get up and try to find a solution to his problem. However, some problems were beyond his control, so he chose to leave them to the Almighty and ask for patience. He shares:

What I feel is that life is very difficult. But if I go back, that would be a failure. This is one. Second, how to find a job in my home country, that's also not easy. Still, there may be a better way in Malaysia. So, I endure, I have no way to escape it until I find a way here.

\section{Positive Reappraisal}

In this study, students identified positive reappraisal as an effective strategy to reduce stress and move on. For example, a student would always try to remember how other people who had the same experience eventually succeeded and managed to overcome the problems. Also, she would remind herself why her parents had sent her here to study abroad. The difficulties she was experiencing in the new environment would make her learn and help her grow up as a person. She had much to be thankful for and there were others who had it much harder in life. Iris reported that:

When I face problems like this, it's, yes, it goes to everyone you know. It's not like you are not alone, so I look up to people who've been here when they had nothing, too, and now they are somebody. And I also know that the reason why my parents sent me here... I would just simply compare myself with people who don't have what I have, you know. Because, for example, I have such a good life that I'm really thankful for.

\section{Religious Faith}

The participants in this study reported that their faith helped them tremendously in coping with their situation. Merak explained that faith and religious conviction was part of his life as a Muslim by saying:

My 'Musliminess', my religion was a very motivating factor. Because from the beginning I chose a Muslim country for my study because I could stay positive, stay motivated because I can practice my religion freely. At the same time, I'm applying my religious and Islamic principles to what I do in a foreign country, especially, uh, in my 
studies. So, I always wanted to learn more about Islam and its principles. Religion always was part of my studies, part of my life, and was part of my socialization in my living, my life, whole life, yeah.

Alkaid noted:

Yes, huh, religion makes me calmer, when times are difficult. It gives me comfort.

\section{Support System}

The interviewed students listed the following seven (7) sources of help for their adjustment issues namely self, academic staff, friends, other international students, family support, prayer, and Office of International Services

\section{Sense of Self-Direction}

The interviewees shared that having a goal in life is important. According to the participants, knowing what one wanted to receive from a university made it easier to adjust one's energy and find opportunities for oneself. On how to best motivate herself Iris reported:

I have got to know about something call vision boards, so what are vision boards? It's like the thing you vision yourself in a few years' time you achieve this. So, I always have all these kinds of visions of me that I can, I would achieve this and that. So, this has really helped me coping with my problems.

Mizar commented that:

I always read some motivating books and set my own goals and work for them.

\section{Academic Staff}

All of the Muslim-Chinese International students participating in this study shared that they had a good relationship with their lectures. Alkaid also received a lot of help and support from his lecturers and his friends. He explained:

I had a lot of help from my teachers. Uh, I will go talk to them sometimes and we have some teachers who are very friendly with us. They talk with us on Facebook, and not just about study, about other things. And, huh, sometimes at lunchtime we eat together with classmates and senior students, and our seniors mostly tell us how it is. So, those are very good supports.

\section{Friends}

All the interviewed students liked to seek for help from their friends, either from their local friends or other international friends. Rose mentioned that:

My best friend is from Indonesia, she is from the same department with me, she is also encouraging ... Sometimes I had difficulties in my study, so she helped me to explain the class content and encouraging me, Sometimes we discuss our class together, we have a discussion for our exam.

\section{Family}

Most of the students were willing to share their problems with their family members. Some of them were not willing to share their problems with their parents, but they shared them with their siblings as their parents might become worried. Three participants were married and were living with their families in Malaysia. Rose, commented: 
Uh, the most useful method to overcome my difficulties is I tell my feeling to my husband. It's very important for me when I'm angry or upset that he knows it very fast. I tell my husband everything about my feeling and he gives me good advice and good suggestions. He encourages me very well.

\section{Prayer}

The participants in this study reported that they were attracted by the Islamic environment in Malaysia. As believing and practicing Muslims, they used prayer and supplication to help them overcome their difficulties and put their minds and hearts at ease. Lily commented that:

When I have little depression, stress, when I pray, I feel like, how to say, someone is looking at me. God is testing us. Even I think that here is hikmah behind the difficulties, so because of religion, all of the things will go one day, so I become positive for everything. And then I try to believe everything will be fine one day. So, I think for this in my life religion plays a very good role.

\section{Office of International Services (OIS)}

The interviewed students shared that when they have some problems such as financial problems, sometimes they chose to go to International students' affairs to ask for help. Mirza shared:

When I have financial difficulties firstly, I try to settle myself, find some part-time job, do some business, ask help from my parents. Since I live with my family here, so I always facing these financial difficulties, then I go to the International Student Affairs to ask for help, and they did help me once.

\section{Facilitators and Barriers}

When asked about the crucial factors that helped or hindered the adjustment, their answers focused on the Islamic environment, English as a medium of instruction, and the good education system. As impeding factors were mentioned loneliness, homesickness, food, climate, and financial issues. Merak reported that:

The facilitating factor is the Muslim culture of Malaysia, while the impeding one is the complete different tropical climate versus the Mediterranean climate of our homeland." Rose had a similar answer and said, "The Islamic environment in Malaysia always motivates me to continue my studies here, while financial difficulties give me lots of pressure and stress.

Mizar explained:

The facilitator for me is the book, motivating books that can help me to endure the difficulties. A Few hindering factors I have been always lack of money. In a foreign land, life is not easy because we have no parents, no relatives, and friends left behind. When financial problems added to it, it makes life more difficult. The weather is another important discourager for me. I'd rather have cold weather.

\section{Experiencing Growth}

The study participants felt that their experience of studying and living abroad had changed them and made them grow as persons. They explained that their academic ability and English 
had improved. They acknowledged having become more open-minded and culturally adjusted. Their social skills had improved, and they had become more mature and self-reliant.

\section{Academic Ability Growth}

Here, the participants shared that their academic ability and English language proficiency had improved as a result of studying in Malaysia. For instance, Alkaid mentioned that:

Malaysian education in English, that helps when you go to other places, and, uh, the courses, some of the university courses are in line with the British education system, so that is also recognized in many countries. Uh, so, this is the greatest advantage. It would help us to have more job opportunities.

\section{Maturation and Independence}

The interviewed students expressed that they were 'growing up' and were becoming more mature and more independent while living abroad. They had understood their responsibilities in life and appreciated more what their parents had done for them. Lily explained:

Before I studied in university, uh, I always depended on my parents, I just followed what they chose for me. but later on, I chose by myself. And then I learned how to choose and make decisions.

Merak added:

I got more independent and culturally adaptive since it has given me the opportunity to learn about other cultures and improve my communication skills.

\section{Becoming More Open-Minded}

The students reported that their way of thinking had changed as a result of coming to Malaysia and being exposed to a different environment. The multi-ethnic and multi-cultural environment had taught them to become more understanding and welcoming of those differences. Lily mentioned that:

By studying in Malaysia, uh, I meet a lot of people who are coming from different countries and different cultures, different languages, so I've learned a lot of things from them. Uh, and I also improved my language skills and improved my social skills and understanding of others. And my mind opened, and then I will think something broadly.

The participants acknowledged that the looked at matters differently now and had learned to be more understanding and welcoming of the differences between people. In summary, the participants in this study expressed their view that their personal growth included their academic ability and knowledge, maturation and independence, and perspective. 


\section{Discussion}

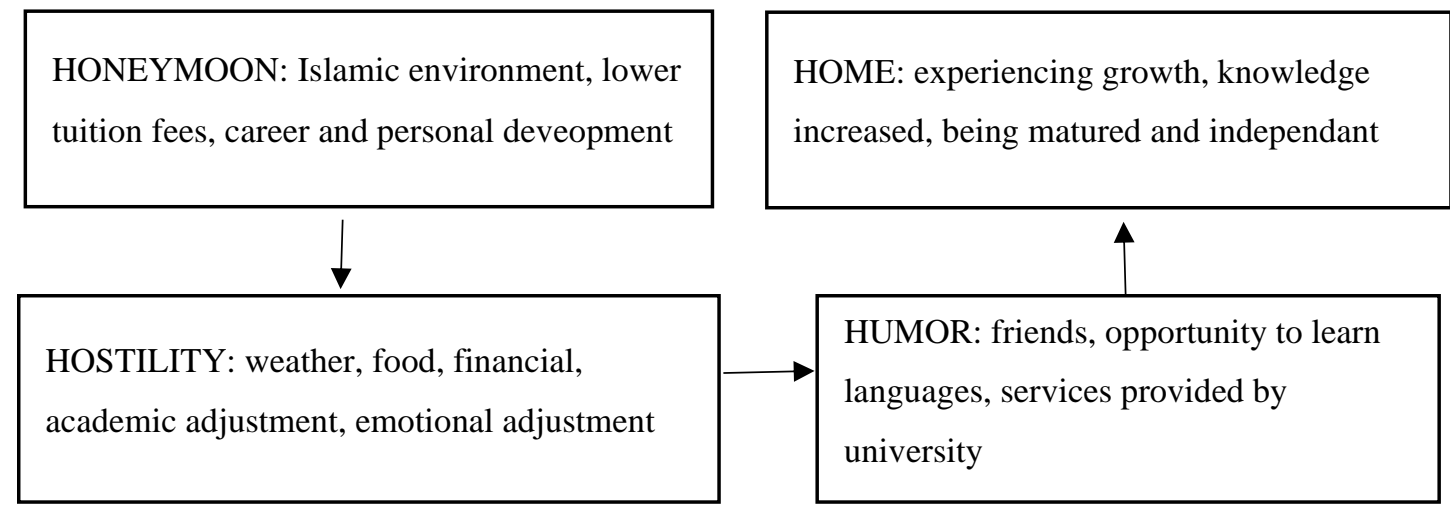

\section{Graphic 1: U Curve Hypothesis of Chinese Students' Adjustment and Coping Methods}

Based on the U-Curve model, the frustrations of our participants could easily be recognized. Our participants felt at home when their sources of happiness were related to their beliefs and that they could improve their English. In terms of their personal development, after finishing their studies here they looked forward to obtaining a degree and embark on their future career path. Besides, the tuition fees in Malaysia were lower than in other countries such as Australia. Our participants felt that Malaysia was the right place to fulfill their dream. Also, it was far easier to obtain a student visa for Malaysia than for Australia or the United States.

The hostility phase can be equated with the 'Facing Difficulties' theme where the participants described the culture shock, they had experienced. Now, the new 'interesting' things in the new surrounding were not interesting anymore and they became acutely aware of what they were missing from home. This cultural mismatch was difficult, tough and challenging. The participants had to bear with the incongruity of the local food and climate. Nothing was like it had been at home. On top of that, it was difficult to secure financial assistance or obtain a work permit, which further aggravated their financial constraints. The social-cultural adjustment did not work at this point since it was difficult to communicate with the locals who preferred to speak in Malay rather than in English. If they spoke English, our participants' English was not on par with them as they had only started to learn the language.

The experienced humor phase signaled their level of adjustment achieved after figuring out ways to correct their own initial misconceptions about the new place and its strange surroundings. This required them to interact more with the locals, immerse themselves in the local culture, and learn to see its positive side. Also, they could accept the help and support provided by the university. At this point, our participants were expected to discover that their university was providing counseling services. These counseling services were not limited to students suffering from mental health problems, but rather to assist and offer ways to help students cope with their problems.

The process of acculturation was completed on level 4 when our participants felt at home. Although not so many of them managed to feel completely feel at home after their relatively short stay in Malaysia, some participants had accepted Malaysia as their second home. The underlying circumstances for a home were established by the participants' belief that it had to be peaceful and include a moderate Islamic environment. 


\section{Conclusion}

The number of international students is increasing year by year, hence, the adjustment issues of international students are given more attention by researchers worldwide. Malaysia currently attracts many students from China and will continue to attract many more students as the number of Chinese students choosing to study abroad is rapidly increasing. Although Malaysia has been quite successful in attracting international students, there is a lack of research on the adjustment of Muslim-Chinese minorities studying in Malaysian universities. The result of this study indicated that all six participants continued to experience adjustment challenges, even after years of living in Malaysia.

These students developed a better understanding of the challenges and opportunities associated with being international students. The challenges they were facing included general living challenges, psychological challenges, social and cultural challenges, and academic challenges. The most common problems experienced by the participants were climate and food categorized under social and cultural challenges together with psychological challenges. Since the participants came from the Xinjiang province which has four seasons, they had to adapt to the hot and humid climate in Malaysia. They were also not accustomed to rice as their staple food.

Secondly, our participants also faced considerable communication problems, also included among the psychological and social and cultural challenges. Our participants had difficulty in establishing personal relationships with the locals due to cultural differences, even though both groups shared common Islamic norms and values. Five participants professed to have very good social skills, however, three of them found it hard to make friends with their local peers. They felt that they had failed in being accepted into their friend circles and did not quite understand the reason for it. Some believed that the local students were reluctant to talk to international students due to the language barrier. However, two participants felt that they could be friends with the local students by showing interest in learning their language and culture.

Thirdly, academic challenges were compounded by the different systems of education between the two countries. The study participants appreciated the useful course content and were satisfied with the educational system in Malaysia. Previously they had only known memorization and individual projects, and the new learning environment challenged them with group discussions and group projects. Their poor English language proficiency added to their challenges as the students had difficulty to absorb the course content and follow the lectures. They also struggled with their course assignments, which constituted a considerable source of pressure and stress for them.

Regardless of the challenges, certain coping mechanisms and strategies were used by them in order to remain afloat. The participants refused to go for the counseling provided by the university and instead preferred to handle their problems alone. According to Cheung (2011), Chinese students prefer to deal with their problems on their own and seek support from their families, friends, and community leaders. As expected, our participants were unwilling to share their problems with strangers. Hence, they focused on problem-solving by direct action or seeking the help and support of close ones. The other coping mechanisms used were avoidance, discharging emotions, self-motivation, and spirituality. Two students tended to discharge emotion through sports activities while avoiding any sort of negativity. The other three students used avoidance by removing their focus from the problem through reading, watching a movie or meeting up with friends. In terms of spirituality, our participants resorted to praising and giving thanks to Allah and asking for patience. 
Also, our participants felt that the experience of studying and living in Malaysia had changed them and facilitated their personal growth. They believed that studying abroad had improved their academic competencies and their English language proficiency. In terms of maturity, they felt that they had become stronger, more resilient and more self-reliant. They had learned to be responsible individuals and were more appreciative of the sacrifices and efforts made by their parents by sending them to Malaysia for their tertiary education. They were also more understanding and welcoming of cultural differences than before. They could envision Malaysia as a second home since it was a peaceful country with many good opportunities to learn, not only secular knowledge but also Islamic knowledge that is applicable to modern society.

\section{Implication of The Study}

All of our participants faced a language barrier challenge due to their lack of English language skills. In China, English was not a compulsory subject and only offered as an extra-curricular subject for minority Uyhgur students. Here, the Malaysian universities would serve their international Chinese students better by offering additional English language courses that are tailored to their needs in terms of adapting to the new environment. In Malaysia, currently, though many universities and colleges have English enhancement courses, however, they are not designed to support their overall adjustment process. Besides, universities could increase the international students' awareness of the available counseling services for students.

Most of the Muslim-Chinese international students reported to have difficulty in dealing with local students in their daily interactions. Considering this obstacle, universities should provide more social programs that could bring international and local students together. Such programs would help diminish the perceived cultural mismatch and deconstruct the cultural stereotypes entertained on both sides. It would also help ease the transition process and allow international students to integrate into Malaysian society.

\section{References}

Altbach, P.G., L. Reisberg \& L.E. Rumbley.(2009). Trends in global higher education: Tracking an academic revolution. United Nations Educational, Scientific and Cultural Organization (UNESCO), Paris.

Bohm, A., Davis, D., Meares, D., \& Pearce, D. (2002). Global student mobility 2025: Forecasts of the global demand for international Higher Education. Sydney: IDP Education Australia.

Brown, L. (2008a). The adjustment journey of international postgraduate students at a university in England: an ethnography (Doctoral thesis). Bournemouth University, Enland, U.K. Retrieved from http://eprints.bournemouth.ac.uk/10305/1/Lorraine_Brown.pdf

Cheung, P. T. A. (2011). Depressive symptoms and help-seeking preferences among Chinese (including mainland China, Hong Kong, and Taiwan) international students. Dissertation Abstracts International Section A: Humanities and Social Sciences, 71, 3790.

Creswell, J.W. (2013). Qualitative inquiry and research design: Choosing among five approaches (3rd ed.). Thousand Oaks, CA: Sage

Cushner, K. McClelland, A. \& Safford, P. L. (2003). Human diversity in education: An integrative approach (4th ed.). New York, NY: McGraw-Hill.

De Araujo, A.A. (2011). Adjustment issues of international students enrolled in American colleges and universities: A review of the literature. Higher Educ.Stud.,1:2-8. 
Dyson, R and K. Renk.( 2006). Freshmen adaptation to university life: Depressive symptoms, stress and coping. J. Clin. Psychol,62, 1231-1244.

Gebhard,JG.(2010).What Do International Students Think and Feel? Adapting to U.S.College Life and Culture. University of Michigan Press, Ann Arbor, Michigan, ISBN13:9780472034062, Pages:174.

Gebhard,JG.(2012). International students' adjustment problem and behaviors. J.Int. Students, 2,184-193.

Kuo, Y.H. (2011). Language challenges faced by international graduate students in the United States.J. Int.Students, 1,38-42.

Lazarus, R., \& Folkman, S. (1984). Stress, Appraisal, and Coping. New York: Springer.

Lichtman, M. (2006). Qualitative Research in Education: A User's Guide. Thousand Oaks, California: Sage.

Lin, J. C. \& Yi, J. K. (1997). Asian International students' Adjustment: Issues and Program Suggestions. College Student Journal. 31(4), 473-479.

Mehdizadeh, Narjes \& Scott, Gill. (2005). Adjustment problems of Iranian international students in Scotland. International Education Journal, 6(4), 484-493.

Mori, S.C. (2000). Addressing the mental health concerns of international students. J. Counsel. Dev.,78,137-144.

Myers-Walls, J.A., L.V.Frias, K.A.Kwon, M.J.M.Ko and T.Lu.(2011). Liv ing life in two worlds:Acculturative stress among Asian international graduate students parents and spouses. J.Comp. Family Stud.,42,455-478.

Paige, R.M. (1990). International students: Cross-cultural psychological perspectives. In R.W. Brislin (Ed.), Applied cross-cultural psychology: Cross-cultural research and methodology series, 14, 367-382.

Sherry, M., P.Thomas \& W.Chui.(2010). International students: Avulnerable student population. Higher Educ.,60,33-46.

Suseela Malaklolunthu \& Poovaikarasi Sateyen Selan(2011). Adjustment problems among international students in Malaysian private higher education institutions. Procedia Social and Behavioral Sciences, 15, 833-837

Wan T, Chapman DW, Biggs DA. (1992). Academic stress of international students attending U.S. wo University. Research in Higher Education,33(5):607-622.

Yusliza, Mohd. \& Yusoff. (2011). International students' adjustment in higher education: Relations between social support, self-efficacy, and socio-cultural adjustment. Australian Journal of Business and Management Research, 1(1), 1-14.

Zolfaghari, A. \& M.S. Sabran.(2009). Internationalization of higher education:Challenges, strategies, policies and programs. Online Submission, 6,1-9. 